\title{
A FRENTE "PIONEIRA" NA AMAZÔNIA: LUTA E RESISTÊNCIA SERINGUEIRA E A INVENÇÃO DAS RESERVAS EXTRATIVISTAS
}

\section{THE "PIONEER" FRONT IN THE AMAZONIA: STRUGGLE AND RUBBER TAPPER RESISTANCE AND THE INVENTION OF THE EXTRATIVIST RESERVES}

\section{RESUMO}

O presente trabalho objetiva debruçar-se sobre a história da criação das Reservas Extrativistas - RESEX, a partir da análise da luta e do envolvimento político dos seringueiros na Amazônia contra o avanço destrutivo da frente "pioneira". O processo de ocupação capitalista da região amazônica trouxe imbricado a si fragmentações da coerência territorial endógena mediante a alteração das formas pretéritas de uso do território, despertando diversas tensões sociais na floresta.

palavras-chave: Amazônia; Fronteira Agrícola; Reservas Extrativistas; Pluralismo Jurídico; Direito Ao Território.

\begin{abstract}
The present work aims to study the history of the creation of Extractive Reserves, based on the analysis of the struggle and the political involvement of the rubber tappers in the Amazon against the destructive advance of the "pioneer" front. The process of capitalist occupation of the Amazon region has brought to itself fragmentations of the endogenous territorial coherence by altering the past forms of land use, arousing various social tensions in the forest.
\end{abstract}

keywords: Amazonia; Agricultural Frontier; Extrativist Reservations; Juridical Pluralism; Right To Territory.

\footnotetext{
${ }^{1}$ Mestrando em Direito Agrário pela Universidade Federal de Goiás - UFG, Universidade Federal de Goiás. (Brasil). E-mail: advgdanieloliveira@gmail.com

${ }^{2}$ Mestre e Doutora em Direito pela Pontifícia Universidade Católica de São de Paulo - PUC-SP, (Brasil). Professora titular da Faculdade de Direito da Universidade Federal de Goiás - UFG. Bolsista produtividade em pesquisa CNPq. Email: mcvidotte@uol.com.br
} 


\section{INTRODUÇÃO}

A Amazônia, que povoa o imaginário de muitos e desperta sentimentos antagônicos e que por vezes funcionam como combustível para os conflitos que lá se instauram, éadmirada por sua beleza, temida por sua selva, cobiçada por sua biodiversidade ou pela extensão de suas terras. Nesse antagonismo de paixões, em algumas ocasiões é exaltada por seus rios, fauna e flora e, em outras, considerada uma região vazia, atrasada e hostil, dessa forma recebendo os mais variados nomes que expressam essas paixões, como "Paraíso sobre a Terra", "Terra sem homens", "Inferno Verde" etc.

Vários foram os projetos para "povoar", "dominar", "integrar", "lucrar" e vários outros verbos que expressem a vontade capitalista de apropriação da região amazônica e de suas riquezas, sempre velados por slogans como o desenvolvimento e a integração da região, porém esses projetos mostraram-se sempre incoerentes com a realidade amazônica, gerando ao invés de "progresso" e "desenvolvimento", a expropriação de populações tradicionais, invasão de terras indígenas, grilagem de terras públicas, concentração fundiária, processos de violência e morte. Nesse sentido, a ocupação da Amazônia é permeada por migrações e tensões sociais de várias espécies, transitando por períodos políticos e econômicos marcados por especificidades que orquestram o tom e o ritmo dos conflitos na região.

Importante destacar que a ocupação da Amazônia se dá de forma complexa e heterogênea, comportando, historicamente, migrantes de todo o país que se deslocavam para a região, atraídos pelos vetores político-econômicos de cada período, cada qual com seu interesse.

Com base nisso, este artigo tem por objetivo analisar o contexto histórico, desde o início do ciclo da borracha, até o seu declínio no início do século XX, conjuntamente com os planos de colonização elaboradospelo regime militar, especialmente na década de 70 , traçando a relação desses momentos históricos com o processo de elaboração e institucionalização das Reservas Extrativistas a partir da análise da luta e do envolvimento político dos seringueiros na Amazônia contra o avanço destrutivo da frente "pioneira", pois a discussão sobre as RESEX passa pela discussão do processo de ocupação da Amazônia enquanto fronteira, enquanto lugar vasto e "vazio" que precisava ser ocupado, desbravado, desenvolvido, assim atualizando o mito colonial do vazio demográfico que se perpetua sempre impiedoso para as populações precedentes, sejam aquelas que mantém um vínculo originário com o território ou aquelas que o constituíram historicamente. E, nesse sentido, é importante destacar que a história da floresta é, também, a história dos humanos, das mulheres 
e dos homens que ali resistem aos ataques cruéis do descaso estatal, da sede gananciosa do agronegócio, da ignobilidade da apropriação estrangeira dos saberes tradicionais e da biodiversidade local, dentre outros vários exemplos que encheriam linhas e linhas e, sempre, esboçariam a triste realidade imposta aos povos e comunidades tradicionais na Amazônia, talvez, sendo o mito do vazio demográfico o mais cruel deles, pois ao desconsiderar a presença humana na região amazônica, está a se desconsiderar o direito de existência dos que estão invisíveis aos olhos do Estado e das forças hegemônicas que o controlam.

\section{1 - AMAZÔNIA, "INTEGRAR PARA NÃO ENTREGAR": O MITO DO VAZIO DEMOGRÁFICO, O AVANÇO "PIONEIRO" E O SURGIMENTO DA RESERVA EXTRATIVISTA}

\section{1 - Do Auge ao Declínio: Os Ciclos da Borracha na Amazônia}

No fim do século XIX o ciclo da borracha ou "ouro negro", sob forte influência do capital estrangeiro, marcou um dos principiais momentos econômicos da Amazônia, atraindo um exército de homens que fugiam das secas e da miséria no Nordeste do país, que submetidos a um sistema de aviamento, eram subjugados a condições subumanas de vida nos vastos seringais abertos nos vales amazônicos.

A exploração do látex, apesar de guardar contradições sistêmicas, tornou-se símbolo do capitalismo industrial e financeiro na Amazônia em razão dos altos preços da borracha no mercado externo, aquecido pela segunda revolução industrial e pelo advento do automóvel (ARBEX JÚNIOR, 2005).

A expansão econômica e populacional da região, promovida pela atividade seringueira, pode ser entendida pelo que José de Sousa Martins classifica como frente de expansão, pois teve impacto direto nas populações indígenas da região. A exemplo disso, a construção da Ferrovia Madeira-Mamoré, considerada por alguns à época como a "deusa do progresso", a "modernidade na selva". A construção dessa ferrovia afetou alguns povos indígenas que estavam "em seu caminho", como os Karipunas, os Mundurukus, os Parintintins, os Kaxararsi, os Pakaa-Novas, Muras e os Guaravos, e não por acaso trouxe constantes choques entre índios, seringueiros e trabalhadores (FERREIRA, 2005), o que é característico da frente de expansão. 
Todavia, foi passageira a euforia econômica do período da borracha, que chegou a ser o segundo produto da pauta de exportações brasileiras, ficando atrás apenas do café. O declínio do primeiro ciclo da borracha deu-se em menos de três décadas após seu início, com o contrabando de sementes dasárvoresseringueiras para a Ásia, onde os ingleses passaram a cultivar vastas áreas de seringal de forma racionalizada e moderna, otimizando assim a produção da borracha e tornando o preço do produto menor do que o brasileiro, dominando o mercado internacional e fazendo ruir a economia seringalista na Amazônia.

Alguns anos mais tarde, precisamente na década de 40, a atividade seringueira ressurgiu em virtude da ocupação do Sudeste asiático pelas forças japonesas, obstruindo o comércioda região que era a principal exportadora de borracha do mundo naquele período. Uma vez mais, foram recrutados trabalhadores, principalmente do Nordeste, para a Amazônia, no que ficou conhecido como a "Batalha da Borracha". Nessa nova fase de extração do látex, seriam necessários, pelo menos, cem mil novos trabalhadores para se alcançar o nível de produção esperado pelos Estados Unidos que financiaria a produção da borracha amazônica, cabendo ao governo brasileiro o recrutamento dos trabalhadores necessários para os seringais. Em todo país, aliciadores reforçavam os velhos mitos do eldorado amazônico a fim de convencer trabalhadores a se alistarem como soldados da borracha e assim cooperarem na vitória aliada.

O presidente à época, Getúlio Vargas, falava em um "plano de reerguimento da Amazônia", afirmando que todo o país deveria voltar-se para o Norte, "com desejo patriótico de auxiliar o surto do seu desenvolvimento" (SANTOS, 1989). Assim, com a intenção varguista de centralização política do Estado nacional, em oposição à velha ordem de oligarquias regionais, a Amazônia passa a ser pensada em termos de integração no Estado nacional (ARBEX JÚNIOR, 2005), sendo o destino final do que se denominou a época de "Marcha para o Oeste".

No entanto, o nível de produção de borracha na Amazônia foi drasticamente menor do que o esperado, o que fez com que o governo norte-americano cancelasse todos os acordos que se referiam à borracha amazônica tão logoquea guerra acabou, levando novamente ao declínio da economia seringalista. Foi o fim da "Batalha da Borracha", porém não das batalhas de seus soldados, alguns regressaram para suas regiões de origem, outros criaram vínculos com a floresta e nela decidiram viver.

Posteriormente, Juscelino Kubitschek seguindo as linhas mestras da política varguista para a Amazônia, lança seu plano de metas desenvolvimentista, que incluiu a construção de rodovias ligando a capital nacional à Região Norte, nas décadas seguintes as 
rodovias construídas por JK, Belém-Brasília e Cuiabá-Porto Velho, se tornaram os dois principais eixos de ocupação daquela região (ARBEX JÚNIOR, 2005).

Anos mais tarde, com o golpe militar em 1964, os militares acrescentam ao desejo de "conquista" da Amazônia a ideia da doutrina de segurança nacional, como um pressuposto de soberania do país e, com esse discurso nacionalista, Castelo Branco sustentava em 1966 a tese do "Integrar, para não entregar", com vistas a fomentar um novo movimento de ocupação da região amazônica. Nesse período, o Estado sob a batuta golpista, se mostra alinhado às ideias keynesianas, se pondo como articulador e regulador das políticas de crescimento econômico. $\mathrm{Na}$ década de 70, a ditadura investiu maciçamente em infra-estrutura viária, ferroviária e energética e criou empresas estatais associadas ao capital privado nacional e transnacional, como o Projeto Grande Carajás (ARBEX JÚNIOR, 2005).

Nesse período, boa parte dos seringalistas vendo-se endividados e sem expectativa alguma de voltar a ter lucro com a exploração dos seringais devido à nova política econômica para a região, decidem vender suas terras aos fazendeiros, vindos principalmente do Sul e Sudeste, e esses por sua vez, desejosos de por abaixo a floresta para dar lugar à pecuária. No entanto, os novos donos encontraram os seringueiros que estavam instalados na condição de posseiros, momento esse de tensão, pois os fazendeiros retiravam de forma violenta os seringueiros da floresta, arrancando-lhes do lugar que o tempo transformou em reduto.

Em síntese, nesse período foram criadas várias políticas de incentivo visando a ocupação dos "vazios" amazônicos, vazio esse que tornava invisível -àsede gananciosa dos 'pioneiros'-, as gentes, os bichos, as matas, os rios.

\section{2 - A 'Invenção' das Reservas Extrativistas: Luta e Resistência por uma Territorialidade Seringueira}

Nesse cenário de interesses econômicos hegemônicos e de valorização da terra como bem especialíssimo de produção, imprescindível para o "progresso" e "integração" daregiãoamazônica ao restante do país, insere-se a luta dos seringueiros para a permanência na terra e proteção dos recursos ambientais presentes nos espaços por eles reivindicados.

Nessa vereda, constata-se que a RESEX opõe-se ao modelo exploratório desenvolvido pelo Estado brasileiro a partir dos anos 70, com incentivos ascendentes à expansão da pecuária extensiva e das lavouras monocultoras, que transforma(va) a paisagem da floresta em imensas áreas de pastagens.Esse modelo desenvolvimentista, mostra(va)-se 
perverso em vários sentidos, pois além de promover a destruição da rica biodiversidade amazônica, expropria(va) os povos da floresta de seus territórios.

Nesse sentido, as RESEX contrapunham-se aos projetos de colonização da região amazônica, baseados na exploração de atividades agropecuárias, visando, sobretudo, assentar populações regionais, principalmente da região sul do país. Ditos assentamentos, consistiam em padrões geométricos de distribuição do espaço territorial, que dividia a floresta em pequenas glebas individuais, rompendo com a territorialidade tradicional dos povos da floresta, com seus ciclos naturais e produtivos, promovendo a derrubada da floresta e a exaustão do solo. Apesar dos esforços governamentais, os projetos de colonização restaram infrutíferos, mediante a intensificação dos fluxos migratórios para áreas urbanas e de fronteira nas décadas de 70 e 80, e também, pelo número significativo de desistências em virtude das dificuldades e isolamento da região Norte.

Diante disso, em meados dos anos 70 e início dos anos 80, levanta-se o movimento social dos seringueiros contra o modelo de desenvolvimento que implicava em alto custo social e ecológico, na tentativa de defesa da região, travando uma intensa luta pelo direito à terra e aos espaços de vida da floresta.

Cumpre ressaltar que o movimento social dos seringueiros, baseava-se em uma forma de sindicalismo ajustado às especificidades regional, com o aperfeiçoamento estratégico de lutas muito peculiares e mecanismos de ação e linguagem próprios. $\mathrm{O}$ movimento dos seringueiros denunciava o desmatamento descontrolado e as injustiças sociais que decorriam da invasão de seus territórios por fazendeiros do centro-sul do país.Nesse contexto, o movimento social dos seringueiros, divide-se em dois momentos principais: empates e a proposição das reservas extrativistas.

Os "empates" consistiam no enfrentamento direto, mediante ação coletiva em quehomens, mulheres e crianças de mãos dadas formavam um cordão humano cercando as áreas que seriam desmatadas, tentando dialogar com os peões dos fazendeiros que abririam caminho na vegetação para a instalação da pecuária, no intuito de impedi-los de que sangrassem a floresta.

Além do mais, tal ação coletiva e, de certa forma simbólica, visava também, impedir as expulsões promovidas pelos fazendeiros que substituíram os seringalistas após o declínio da borracha, transformando os seringais em fazendas de gado. Daí decorre inúmeros conflitos fundiários, que desaguaram na desterritorialização dos povos da floresta que habitavam tal espaço territorial, inclusive ameaçando sua identidade cultural. 
Em meados dos anos 80, os empates desdobram-se na proposta de criação das reservas extrativistas, como uma opção real de utilização sustentável da terra e dos recursos florestais, contrariando o modelo de exploração na região que restava totalmente distante da realidade socioambiental amazônica.

Em suma, neste momento os seringueiros colocam-se vertical e horizontalmente contrários aos projetos oficiais de colonização que pretendiam dividir suas terras em lotes individuais, propondo uma modalidade própria de reforma agrária, orientada para as características da vida amazônica, como forma de garantir o direito histórico de permanecerem em suas colocações na floresta.

A modalidade de reforma agrária proposta, até então inédita, guardava similitudes com as reservas indígenas, pois propunham a demarcação de áreas destinadas a proteger a floresta amazônica e continuar abrigando a população que tradicionalmente, encontrava-se nesses espaços.

Obviamente, forçoso é perceber que com o advento da Constituição Federal de 1988, algumas populações tradicionais, como os indígenas e quilombolas, tiveram seus direitos territoriais reconhecidos, enquanto as comunidades caiçaras, ribeirinhas e extrativistas etc. apesar de manterem uma relação histórica com os espaços que ocupavam, foram preteridas da tutela constitucional, o que dificultaria ainda mais todo e qualquer processo na luta pela permanência em seus territórios.

A partir de 1985, a luta dos povos da floresta amazônica desloca-se para um ponto de atenção nacional e internacional, passando a ser amplamente discutida nos mais diferentes setores sociais, com destaque para a ideia das reservas extrativistas, dando visibilidade, voz e cor aos seringueiros, protagonistas dessa proposta, e as suas lutas que imersas na beleza de seus ideais transcendiam a sede de apropriação da floresta pela ganância e perversidade dos fazendeiros.

O desenrolar da história leva à efetivação dos direitos pleiteados na luta dos seringueiros pela preservação da floresta e dos laços territoriais que mantinham com o espaço que ocupavam, a luta teve seu ápice com a morte de Chico Mendes, um dos principais atores do movimento seringueiro, o que inclusive retirou-lhe sua principal aspiração, como ser e como líder, de viver para lutar em favor da vida: “Quero viver, para salvar a Amazônia!”.

\section{3 - Fatos e Teoria: Amazônia, um Espaço de Disputas}


A Amazônia foi considerada no período em que está inserida a luta seringueira pelo direito de reconhecimento de uma territorialidade específica, como a última grande fronteira. Nesse ínterim, partindo de uma compreensão sociológica, fronteira pode ser entendida como um período histórico "em que as relações sociais e políticas" encontram-se influenciadas pelo processo de expansão demográfica sob o lema de ocupação de terras "vazias" ou "insuficientemente" ocupadas (MARTINS, 1997).

A partir de 1964, com o estabelecimento da ditadura militar, os projetos de ocupação da Amazônia intensificaram-se de forma "massiva, violenta e rápida", processo que continuou, mesmo com o fim da ditadura e retorno de um regime democrático em 1985 (MARTINS, 1997).

Entretanto, a realidade amazônica não pode ser entendida como uma realidade "à parte em relação ao conjunto da sociedade brasileira", pois a reprodução do capitalismo é processualmente tenso e gerador de conflitos no campo e nas cidades brasileiras, mesmo que a região amazônica se destaque "como área diretamente subordina por esse processo conflituoso, como uma espécie de região problemática", deve-se levar em consideração que tal realidade conflituosa só se justifica em razão "das contradições mais profundas que estão (...) enraizadas na estrutura da sociedade brasileira" (MARTINS, 1982).

Nesse sentido, faz-se necessário destacar que a ocupação da Amazônia - ou invasão como chamou José de Sousa Martins, se deu de forma gradual, portanto não restrita a um único movimento ou pelo mesmo modelo de ocupação, ou seja, houve - e ainda há, tempos históricos diferentes dentro desse processo de ocupação que, cronologicamente, não se sucedem, ao contrário definem-se por condições próprias, pelas singularidades dos sujeitos históricos e pelos modelos produtivos presentes nas frentes desse processo. Dessa forma, no que tange ao surgimento das RESEX, destacam-se dois momentos: um primeiro marcado pela economia da borracha, no qual os seringueiros, vindos principalmente do Nordeste, formam a frente de expansão e, um segundo momento marcado pelo avanço capitalista, tendo como agente o latifundiário, formando a frente pioneira que ferozmente avançava rumo à floresta devorando suas árvores, seus bichos, suas gentes, seus sons, seus risos, seus sonhos, sua paz.

E, é nesse contexto que se dá a conturbada realidade da fronteira, que no Brasil "é uma história de destruição", pois "O que há de sociologicamente mais relevante para caracterizar e definir a fronteira no Brasil é, justamente, a situação do conflito social". Mas, a história da fronteira é também uma história de lutas étnicas e sociais, "uma história de resistência, de revolta, de protesto, de sonho, de esperança" (MARTINS, 1997), e as RESEX são frutos dessa parte da história, foram forjadas nas lutas, esperanças, lágrimas e sangue dos 
seringueiros, pois na verdade "a Amazônia não é nenhum deserto a ser ocupado", uma vez que já estava ocupada "segundo os critérios e as circunstâncias próprias" dos povos que ali estavam, o que se tem com a fronteira, sobretudo com a sua frente pioneira, "é a aplicação de um modelo de ocupação que pretende anular e revogar os modelos anteriores" (MARTINS, 1982), por isso, categoricamente afirmou José de Sousa Martins:

[...] não estamos diante de um processo de ocupação da Amazônia; estamos, na verdade, diante de uma verdadeira invasão da Amazônia, em que os chamados pioneiros não raro se comportam, ante aos primeiros ocupantes, como autênticos invasores - devastando, expulsando, violando direitos e princípios. (MARTINS, 1982, p. 69)

A invasão pioneira tinha ao seu lado a força dos incentivos financeiros do Estado e dos títulos de propriedade que lhe conferiam legalidade, mas os seringueiros tinham a determinação de seus sonhos de permanecer na floresta e resistiram à tirania dos invasores. Nesse cenário de relações sociais divergentes, em que a análise das alianças e confrontos que surgem da ação dos sujeitos traduz a busca por ocupação de diferentes grupos. Isto nos leva a uma importante dimensão na compreensão da constituição e atuação do Movimento Seringueiro: o conflito. Como nos diz ACSELRAD:

Os conflitos ambientais são [...] aqueles envolvendo grupos sociais com modos diferenciados de apropriação, uso e significação do território, tendo origem quando pelo menos um dos grupos tem a continuidade das formas sociais de apropriação do meio que desenvolvem ameaçada por impactos indesejáveis [...] decorrentes das práticas de outros grupos. (ACSELRAD, 2004, p. 26)

E, é do conflito que nasce o direito dos seringueiros perante o Estado, que de certa forma é pressionado pelo caráter ambiental de que se reveste a luta seringueira, especialmente, em um momento de profunda mobilização internacional sobre o meio ambiente. Assim, o direito conquistado é símbolo da resistência e da luta, inclusive frente às forças do próprio Estado, perfazendo-se como uma inovação jurídica desde a origem, dessa forma comportando resistência de vários lados, mas resistindo pela força do ideal contido na ideia de vanguarda de Chico Mendes.

Nesse compasso, tem-se que o processo de ocupação capitalista da região amazônica, trouxe imbricado a si fragmentações da coerência territorial endógena mediante a alteração das formas pretéritas de uso dos espaços, despertando tensões sociais que resumiram-sena luta pela permanência na terra e proteção da floresta pelos seringueiros, pois não está a se falar, tão somente, em uma luta por um espaço físico, mas por uma identidade, por vínculos, memórias etc está a se falar na luta por um território e: 
[...]o território não diz respeito apenas à função ou ao ter, mas ao ser. Esquecer este princípio espiritual e não material é se sujeitar a não compreender a violência trágica de muitas lutas e conflitos que afetam o mundo de hoje: perder seu território é desaparecer" (BONNEMAISON; CAMBRÉZY, 1996, p. 13-14 apud HAESBAERT, 2004 p. 72-73)

$\mathrm{Na}$ árdua luta seringueira por reconhecimento do seu direito ao território, a institucionalização das Reservas Extrativistas significou a materialização da territorialidade seringueira, ou seja, tendo a floresta enquanto um território segundo os vínculos de uma coletividade (BAUMAN, 2003).

A reserva extrativista surge, em âmbito institucional, como fruto da luta histórica dos seringueiros da Amazônia Ocidental, entre o final da década de 80 e início da década de 90, anos mais tarde torna-se a primeira modalidade de unidade de conservação da legislação ambiental brasileira que previa ocupação e utilização sustentável dos recursos naturais, bem como a regularização fundiária dos espaços territoriais para as comunidades tradicionais extrativistas.

\section{2 - ESPAÇOS CONTRA HEGÊMONICOSNA FRONTEIRA: O DIREITO DOS SERINGUEIROS AO TERRITÓRIO}

\section{1 - Contexto Jurídico da Institucionalização das Reservas Extrativistas}

A criação das RESEX tem por trajetória inicial a Portaria n. $^{\circ} 627$, baixada pelo Instituto Nacional de Colonização e Reforma Agrária - INCRA, em 30 de julho de 1987. A tentativa de inserir as RESEX dentro da Política Nacional de Reforma Agrária - PNRA, justificavam-se pela inexistência, à época, de políticas públicas e/ou legislação ambiental que pudesse abarcar o extrativismo sustentado como uma forma possível de proteção ambiental, aliado a isso "às expectativas depositadas na reformulação do conceito de função social da propriedade" que estava sendo construído na Assembléia Nacional Constituinte, indicando a oportunidade de incluir as RESEX, definitivamente, no PNRA (GOMES;FELIPE, 1994).

A Portaria n. ${ }^{\circ}$ 627/87 instituiu os Projetos de Assentamento Extrativista - PAEx, alternativamente ao modelo de projetos de assentamento fundiário executados pelos INCRA até então, propondo duas inovações: a exploração condominial e a concessão de direito real de uso. A exploração condominial desvencilhava-se do tradicional modelo de parcelamento do solo em lotes, que era incompatível com a atividade extrativista seringueira. E, a concessão de direito real de uso impunha uma finalidade específica e previamente determinada para a 
utilização da área e também, a impossibilidade de transmissãointer vivos e a rescisão do contrato quando verificados danos ambientais ou desvio de finalidade.

Na vigência da Portaria n. ${ }^{\circ}$ 627/87, foram instituídos dez projetos de assentamento extrativista, que se estendiam por cerca de novecentos mil hectares e contemplaram mais de três mil famílias.

Posteriormente, com o advento da Constituição de 1988, que pela primeira vez na história constitucional pátria trazia um capítulo específico para tratar do meio ambiente, abrindo espaço na legislação ordinária para o reconhecimento do caráter ambiental de que reveste-se as RESEX, inserindo-as na Política Nacional do Meio Ambiente mediante as alterações da Lei n. ${ }^{o}$ 6.938/81 trazidas pela Lei n. ${ }^{\circ}$ 7.804/89. As RESEX, a partir de então, passam à qualidade de unidades de conservação e ficam sob a responsabilidade do Instituto Brasileiro do Meio Ambiente e dos Recursos Naturais Renováveis - IBAMA.

No ano de 2000 entra em vigor a Lei n. 9.985 ou Lei do Sistema Nacional de Unidades de Conservação - SNUC, que inclui as Reservas Extrativistas, estabelecendo normas e critérios para a criação, implantação e gestão dessas unidades de conservação de uso sustentável e atribuindo ao Instituto Chico Mendes de Conservação da Biodiversidade ICMBio a responsabilidade pela criação e fiscalização das unidades de conservação no âmbito federal.

Complementarmente, no de 2002 entrou em vigor o Decreto $n .^{\circ} 4.340$, com vistas a regulamentar disposições da Lei do SNUC e especificamente sobre as RESEX trouxe a determinação de que o ato de criação dessas unidades de conservação, expressamente, deve conter a população tradicional beneficiária e, que a aprovação do plano de manejo das RESEX deve ser aprovado por resolução pelo conselho deliberativo, devendo o contrato de concessão de direito real de uso estar em conformidade com as especificidades do plano de manejo. Apesar de dispor sobre questões que envolviam, diretamente, povos e comunidades tradicionais extrativistas, nem a Lei do SNUC, tão pouco o seu Decreto regulamentador trouxeram a definição jurídica do que seria "povos e comunidades tradicionais", cabendo ao Decreto n. ${ }^{\circ} 6.040 / 07$ o fazer, definindo no art. $3^{\circ}$, I, que:

Povos e Comunidades Tradicionais: grupos culturalmente diferenciados e que se reconhecem como tais, que possuem formas próprias de organização social, que ocupam e usam territórios e recursos naturais como condição para sua reprodução cultural, social, religiosa, ancestral e econômica, utilizando conhecimentos, inovações e práticas gerados e transmitidos pela tradição. 
Outra definição importante trazida pelo Decreto n. $^{\circ}$ 6.040/07, foi o de território tradicional, como sendo "os espaços necessários a reprodução cultural, social e econômica dos povos e comunidades tradicionais, sejam eles utilizados de forma permanente ou temporária" (BRASIL, 2007).

Importante destacar que a partir da institucionalização das RESEX o Estado se torna sujeito ativo na questão, pois passa a ser responsável pela criação/reconhecimento e consequentemente, regularização fundiária desses espaços socioambientais.

Em suma, juridicamente, as reservas extrativistas são espaços territoriais protegidos pelo Estado a fim de garantir os meios de vida e a cultura de populações tradicionais que tem como atividade o extrativismo vegetal, assegurando o uso sustentável dos recursos naturais da área territorial sob proteção. A área da RESEX pertence ao Estado, porém com concessão do direito real de usoàs populações tradicionais extrativistas, sendo proibida à caça e a retirada comercial de madeira está condicionada a situações especiais e complementares às atividades desenvolvidas, devendo ser feita sob bases sustentáveis, conforme disposição específica no Plano de Manejo. É proibida a criação de animais de grande porte nas RESEX, podendo de forma complementar, serem desenvolvidas a agricultura de subsistência e a criação de animais de pequeno porte. A gestão de cada RESEX dar-se-á por um Conselho Deliberativo, presidido pelo órgão responsável por sua administração e constituído por representantes de órgãos públicos diversos, de organizações da sociedade civil e representantes da população tradicional residente na respectiva reserva.

\section{2 - A 'Invenção' das Reservas Extrativistas Para Além do Monismo Jurídico de}

\section{Outrora}

Partindo de uma concepção sociológica do Direito, pode-se afirmar que a Reserva Extrativista é uma invenção no campo do Direito que nasce por meio das lutas e anseios sociais contra o sistema político-jurídico posto, fincado na realidade capitalista e individual, que ao desprezar os seringueiros, por meio de um novo padrão de organização socioeconômico de ocupação da Amazônia, traz à tona o conflito social, que mediante a organização e mobilização política dos seringueiros que se faz reivindicando justiça social, pleiteando a manutenção de um modo de vida estruturado em uma territorialidade, portanto, sendo em um contexto de exclusão, carências e necessidades materiais que as práticas corriqueiras e insurgentes do movimento social seringueiro, se faz portador potencial "de novas forma de se fazer política, bem como fonte informal geradora de produção jurídica" (WOLKMER, 2015) 
Pode-se dizer que a 'invenção' das RESEX rompe com o monismo jurídico de outrora, ou seja, com a concepção de que o Direito está centrado no Estado, sendo realidades que se confundem, por isso chamado também de estatismo jurídico. Nessa compreensão de Direito que, diga-se de passagem, predomina na práxis jurídica brasileira, só existe o direito estatal, não se admitindo a ideia de qualquer regra jurídica fora do Estado, pois somente ao Estado através de sua "força coativa" se cria o Direito.

O movimento de luta pelo reconhecimento de uma territorialidade específicados seringueiros trouxe o romper com essa práxis, pois fez com que fosse reconhecido o Direito como uma criação social, cabendo ao Estado a função de positivá-lo, isto é, de transformá-lo em norma escrita de acordo com a consciência coletiva que o reivindicava.

Nessa vertente, a compreensão teórica que se tem é que as RESEX representam a adoção de uma nova prática pelo Estado, ou seja, a adoçãodo pluralismo jurídico como corrente teórica a partir do reconhecimento de uma outra fonte do direito que não o próprio Estado, desse modo reconhecendo "a multiplicidade de práticas existentes num mesmo espaço sócio-político, interagidas por conflitos ou consensos, podendo ser ou não oficiais e tendo sua razão de ser nas necessidades existenciais, materiais e culturais” (WOLKMER, 1995).

Verifica-se que partindo das práticas sociais, de resistência e luta, internalizada pelos seringueiros, emergiu "uma nova concepção de direitos mais mutável, elástica e plural, que transcende aos direitos estatais, consagrados nos limites da doutrina imperante e da legislação positiva" (WOLKMER, 2015). O reconhecimento do direito dos seringueiros a um território simboliza o romper paradigmático com o direito monista de outrora, que fincado a uma cultura jurídica tradicional, liberal e formalista, por si só não consegue responder às novas formas, aos conflitos coletivos e às crescentes demandas sociais, permitindo a discussão de novos fundamentos jurídicos, vindos das reivindicações dos novos sujeitos coletivos de legitimação, bem como das formas plurais de revelação jurídica, sendo tal romper, essencial para redefinir e fazer avançar o projeto de uma justiça mais democrática, pluralista e participativa, adequada às contingências histórico-sociais das sociedades latino-americanas, como a brasileira(WOLKMER, 2015).

As RESEX representam a construção de um direito a partir do clamor social dos seringueiros na Amazônia, fruto de uma nova concepção jurídica que finca-se no pluralismo, no reconhecimento de outras normatividades, territorialidades, percepções da realidade e modos de viver. De igual forma, representa a conquista de um sonho para àqueles que um dia acreditaram ser possível vencer a velha práxis social e jurídica que, historicamente, está enraizada na estrutura da sociedade brasileira. 


\section{CONSIDERAÇÕESFINAIS}

Enfim, tem-se que o espaço territorial, principalmente sua (re)distribuição, constitui uma eterna e difícil questão nacional. Tal questão encontra-se presente ao longo da história do Brasil, porém com formatos distintos.

Neste passo, à questão da terra está presente desde o processo de colonização (1500-1822), mormente a preocupação, num sentido lato, com a ocupação e consolidação territorial. No Império (1822-1889), com a configuração do Estado Nacional e a soberania da integridade do território; na República (1889-1930 - Estado Liberal-Oligárquico), com as articulações das oligarquias regionais; no período Desenvolvimentista (1930-1985), com a constituição da Nação, com o desenvolvimento regional e com a coesão social.

Adiante, na transição política rumo ao Estado Regulador (1985-2002), as voltas com a preocupação de superar a instabilidade política e econômica e inserir-se no processo globalizante, (re)forçando a ideia de modernização das atividades agrárias, visando aumentar a produtividade e impulsionar o crescimento econômico e; no período recente (Estado Indutor, 2003-2010), com a descentralização de políticas e a centralização de recursos para a condução das ações de governo distribuídas no território, sobretudo, aquelas que amparam os latifundiários, haja vista as flexibilizações jurídicas e incentivos econômicos que são dispensados a estes.

Assim, importa dizer que apesar da crise política e econômica que arrasta o país para o retrocesso socioeconômico, vêem-se cortes orçamentários para vários segmentos econômicos e sociais. Contudo, a contragosto do cenário de crise, a dotação orçamentária estatal para o setor agropecuário, foi aumentada.

Diante disso, não faltaram argumentos a fim de justificar tal contradição, uns alegam que o setor sustenta a balança comercial brasileira e que o Produto Interno Bruto PIB, depende majoritariamente do setor agropecuário, outros apontam para o fortalecimento da base ruralista no Poder Legislativo, que força o favorecimento mediante políticas públicas para tal setor.

Neste cenário, político-econômico, de contradições e nuances históricas, insere-se a questão territorial, sobretudo a questão do acesso à terra por minorias marginalizadas pelo sistema neoliberal que preside as instâncias institucionais, inviabilizando o desenvolvimento de instrumentos e/ou efetivação destes, para que aqueles que reivindicam 
seus direitos territoriais, sejam enxergados além dos espaços que reivindicam, e passem a serem tratados como sujeitos de direitos.

Tal mudança de paradigma rompe com a linha tênue que há entre a subjugação dos direitos territoriais das minorias ante os interesses econômicos, buscando assim a justa distribuição territorial e rompimento com a visão desenvolvimentista do campo conduzido pelas rédeas do mercado externo.

Neste cenário de interesses econômicos hegemônicos e de valorização da terra como bem especialíssimo de produção, imprescindível para o equilíbrio da balança comercial do país, insere-se a luta das comunidades tradicionais extrativistas para o acesso à terra $\mathrm{e}$ proteção ambiental dos espaços por eles reivindicados.

Logo, a criação de um reserva extrativista é uma forma de assegurar direitos territoriais de populações que ocupam tradicionalmente áreas sobre as quais, também, recai o interesse de preservação ecológica. Logo, está-se diante de direitos coletivos e difusos que permeiam a questão das RESEX, pois de um lado estão os direitos territoriais de um grupo que intenta ser reconhecido como tradicional e, de outro o direito a um meio ambiente ecologicamente equilibrado.

Por fim, imperioso destacar que a construção jurídica dos RESEX assenta-se sobre um romper paradigmático e pragmático do Direito, pois apesar de "haver resistência por parte da cultura oficial normativa e de seus aparatos burocráticos, a comprovação dessas manifestações de "legalidade paralela ou concorrente" a partir da luta por direitos à terra torna-se, gradativamente, inconteste e por demais evidente” (WOLKMER, 2015).

Assim, tendo o Direito como um processo, dentro do processo histórico, não como algo pronto, definido, perfeito e acabado, mas como algo que se enriquece, que se faz e se refaz por meio dos anseios sociais, do clamor "de libertação das classes e grupos ascendentes e que definha nas explorações e opressões que o contradizem, mas de cujas próprias contradições brotarão as novas conquistas" (LYRA FILHO, 2006).

\section{BIBLIOGRAFIA}

ACSELRAD, H. As práticas espaciais e o campo dos conflitos ambientais. In: . (Org.) Conflitos ambientais no Brasil. Rio de Janeiro: RelumeDumará: Fundação Heinrich Böll. 2004. p. 13-35.

ALLEGRETTI, M. H. Reservas Extrativistas: parâmetros para uma política de desenvolvimento sustentável na Amazônia. In: ARNT, R. (Ed.) O destino da floresta: reservas extrativistas e desenvolvimento sustentável na Amazônia. Rio de Janeiro: RelumeDumará; 
Curitiba, PR: Instituto de Estudos Amazônicos e Ambientais, Fundação Konrad Adenauer, 1994. p. $17-47$.

M. H. A construção social e políticas ambientais: Chico Mendes e o Movimento dos Seringueiros. 2002. 827 f. Tese (Doutorado em desenvolvimento sustentável - Gestão e política ambiental). Centro de Desenvolvimento Sustentável, Universidade de Brasília, Brasília.

ARBEX JR., José. "Terra sem povo", crime sem castigo: pouco ou nada sabemos de concreto sobre a Amazônia. In: TORRES, Maurício. Amazônia revelada: os descaminhos ao longo da BR - 163. Brasília: CNPq, 2005.

BAUMAN, Zygmunt. Comunidade: a busca por segurança no mundo atual. Rio de Janeiro: Jorge Zahar Ed., 2003.

BRASIL. Constituição, 1988.

BRASIL. Lei $\mathrm{n}^{\circ}$ 6.938, de 31 de agosto de 1981.

BRASIL. Lei nº 9.985, de 18 de julho de 2000.

BRASIL. Decreto nº 6.040, 07 defevereirode 2007.

FERREIRA, Manuel Rodrigues. A ferrovia do Diabo. São Paulo: Melhoramentos, 2005.

GOMES, Manoel Eduardo A.C. \& FELIPE, Luis Daniel. Tutela Jurídica sobre as ReservasExtrativistas. In: O destino da Floresta: reservas extrativistas e desenvolvimento sustentável na Amazônia. Rio de Janeiro, Relume-Dumará; Curitiba, Instituto de Estudos Amazônicos e Ambientais, Fudação Konrad Adenauer, 1994.

HAESBAERT, R. Territórios alternativos. São Paulo: Contexto, 2002.

LYRA FILHO, Roberto. O que é Direito. (Coleção Primeiros Passos). São Paulo: Brasiliense, 2006.

MARTINS, José de Sousa. Capitalismo e Tradicionalismo: estudo sobre as contradições da sociedade agrária no Brasil. São Paulo: Pioneira, 1975.

HUCITEC, 1982.

. Expropriação e Violência: A questão política no campo. São Paulo: Editora

Fronteira: A degradação do Outro nos confins do humano. São Paulo: Editora HUCITEC, 1997.

OLIVEIRA, Ariovaldo Umbelino de. A geografia das lutas no campo - $6^{\mathrm{a}}$ ed., São Paulo: Contexto, 1996.

SANTOS, Roberto Araújo de Oliveira. O genius de uma economia: reflexões e propostas sobre o desenvolvimento da Amazônia. Populações Humanas e Desenvolvimento Amazônico. Belém: UFPA, 1989. 351p. 
WOLKMER, Antonio Carlos. Introdução ao Pensamento Jurídico Crítico. $2^{a}$ ed. São Paulo: Editora Acadêmica, 1995.

Novos Sujeitos Sociais e a Construção Plural de Direito. In: Conflitos Agrários, seus sujeitos, seus direitos/ org. Maria Cristina Vidotte Blanco Tárrega\& Sônia Fátima Schwendler. Goiânia: Ed. da PUC Goiás, 2015. 